\title{
Estudo do processo de dispersão de emissões veiculares em uma microrregião de Belo Horizonte (MG) utilizando simulação numérica
}

\section{Study of the dispersion process of vehicular emissions at a specific site in Belo Horizonte (MG), Brazil, using numerical simulation}

\section{Fernanda Vasconcelos Fonseca Tavares}

Física. Mestre em Ciência e Tecnologia das Radiações, Minerais e Materiais pelo Centro de Desenvolvimento da Tecnologia Nuclear (CDTN)

\author{
Alberto Avellar Barreto \\ Engenheiro Mecânico. Doutor em Engenharia Mecânica pela Universidade Federal de Minas Gerais (UFMG). Pesquisador da Comissão Nacional de Energia \\ Nuclear do Centro de Desenvolvimento da Tecnologia Nuclear (CDTN) \\ Elisete Gomides Dutra \\ Engenheira Química. Doutora em Engenharia Mecânica pela UFMG. Gerente de Qualidade do Ar da Fundação Estadual do Meio Ambiente (FEAM)
}

\section{Vanusa Maria Feliciano Jacomino}

Física. Doutora em Tecnologia Nuclear pela Universidade de São Paulo (USP). Pesquisadora da Comissão Nacional de Energia Nuclear do CDTN

\begin{abstract}
Resumo
O modelo CAL3QHCR (California Line Source for Queuing \& Hot Spot Calculations Refined) foi utilizado para avaliar a contribuição das emissões de material particulado $\left(\mathrm{MP}_{10}\right.$ e $\left.\mathrm{MP}_{2,5}\right)$ de origem veicular na qualidade do ar de uma microrregião do centro de Belo Horizonte (MG). Os resultados de concentração obtidos nas simulações foram comparados com dados experimentais de concentração de $\mathrm{MP}_{10}$ e $\mathrm{MP}_{25}$, obtidos a partir da amostragem desses poluentes em uma estação de monitoramento da qualidade do ar localizada na área de estudo. Para todos os cenários, os valores de concentração previstos pelo modelo foram menores do que os observados. Uma análise de sensibilidade revelou que o fator de emissão veicular é o parâmetro que mais influencia os resultados das simulações, indicando a necessidade de realização de um maior número de pesquisas sobre o tema no Brasil.
\end{abstract}

Palavras-chave: Qualidade do ar; poluição veicular, material particulado, simulação numérica.

\begin{abstract}
The CAL3QHCR (California Line Source for Queuing \& Hot Spot Calculations Refined) model was used to assess the contribution of particulate matter (PM ${ }_{10}$ and $\mathrm{PM}_{2.5}$ ) from vehicular exhausts to the air quality of a specific site downtown Belo Horizonte (MG), Brazil. Concentration results obtained through simulations were compared to the experimental data of concentrations of $\mathrm{PM}_{10}$ and $\mathrm{PM}_{2.5}$ which consisted of collected samples of these pollutants from a monitoring station for air quality located in the area of the study. For all scenarios, the concentration values predicted by the model were lower than the experimental concentrations. The sensitivity analysis showed that the vehicular emission factor influenced the simulation results more than the other parameters, which points out to the need of more researches in this area in Brazil.
\end{abstract}

Keywords: Air quality; vehicle pollution; particulate matter; numerical simulation.

\section{Introdução}

A poluição do ar pode ser definida como a liberação na atmosfera de qualquer substância (partículas ou gases) que altere a constituição natural do ar, afetando negativamente espécies animais e vegetais ou provocando modificações físico-químicas nos minerais (CETESB, 2008; CONAMA, 1990; GODISH, 1997).

Os Padrões Nacionais de Qualidade do Ar - estabelecidos pelo Instituto Brasileiro do Meio Ambiente e dos Recursos Naturais Renováveis (IBAMA) e aprovados pelo Conselho Nacional do Meio Ambiente 
(CONAMA), por meio da resolução CONAMA 03/1990 - definem legalmente o limite máximo para a concentração de um poluente na atmosfera visando proteger a saúde dos seres vivos e o meio ambiente.

A poluição do ar, seja de origem industrial ou doméstica, tem diminuído consideravelmente em decorrência de várias ações governamentais. Entretanto, a poluição do ar causada pela emissão veicular de gases e partículas tem aumentado de forma significativa, uma vez que o número de veículos que circula nas vias de tráfego cresce continuamente (NAGENDRA; KHARE, 2002). Segundo Godish (1997) e Sharma e Khare (2001), a capacidade poluente dos veículos automotores é a maior dentre quaisquer outras atividades desenvolvidas pelo homem. A queima do combustível pelos motores dos veículos libera diversos gases e partículas para a atmosfera, alterando sua constituição original e tornando-a poluída.

Um dos principais poluentes atmosféricos originados das emissões veiculares é o material particulado (MP), classificado em $\mathrm{MP}_{10}$ (diâmetro menor do que $10 \mu \mathrm{m}$ ) e $\mathrm{MP}_{25}$ (diâmetro menor do que 2,5 $\mu \mathrm{m}$ ). Os efeitos do MP sobre a saúde humana dependem de sua maior ou menor capacidade de penetração no sistema respiratório, podendo variar de uma simples crise alérgica a um câncer de pulmão (WHO, 2005).

Nesse contexto, o monitoramento da qualidade do ar torna-se fundamental para a definição de políticas de controle da poluição atmosférica. Por meio da implantação de uma rede de monitoramento, pode-se constatar a evolução das concentrações dos poluentes na atmosfera e aferir a eficácia dos processos de controle de emissões (CETESB, 2008).

A utilização de técnicas experimentais, baseadas principalmente em redes de monitoramento, possibilita o conhecimento, em tempo real, das condições da qualidade do ar somente para as posições onde os dados são coletados. Os equipamentos de investigação da concentração de poluentes são caros e necessitam de uma estrutura para o acompanhamento contínuo das condições de operação, de forma a garantir a qualidade da informação obtida.

Simulações numéricas são ferramentas amplamente utilizadas para avaliar os mecanismos de dispersão de poluentes na atmosfera. Elas fornecem uma estimativa teórica dos níveis de poluentes no ar, bem como informações espaciais e temporais sobre a evolução desses poluentes na atmosfera (SHARMA; KHARE, 2001). As simulações numéricas também são utilizadas para representar cenários futuros, $\mathrm{O}$ que possibilita a antecipação de medidas de controle.

Para expandir o conhecimento sobre a qualidade do ar em uma determinada região de interesse, frequentemente são utilizadas técnicas experimentais em combinação com recursos de simulação. Muitos estudos sobre modelos numéricos têm sido realizados com o intuito de avaliar o impacto das emissões veiculares na qualidade do ar (GOKHALE; KHARE, 2004; MISHRA; PADMANABHAMUTRY, 2003; SHARMA; KHARE, 2001). Dentre os modelos mais utilizados incluem-se: Modified General Finite Line Source Model (M-GFLSM), Particulate Emission Factor
Model (PART5), California Line Source - 3 (CALINE3), California Line Source - 4 (CALINE4), California Line Source for Queuing \& Hot Spot Calculations (CAL3QHC). O desempenho desses modelos tem sido continuamente avaliado por vários autores, incluindo os supracitados, o que contribui para melhorar os resultados das simulações.

O CAL3QHC é um dos modelos recomendados pela Califórnia Environmental Protection Agency (Cal/EPA) e pela United States Environmental Protection Agency (USEPA) e de maior aceitação para avaliar a dispersão de poluentes gerados por fontes móveis (GOKHALE; RAOKHANDE, 2008; MISHRA; PADMANABHAMUTRY, 2003; YURA; KEAR; NIEMEIER, 2007; ZHOU; SPERLING, 2001). Porém, já existe uma versão melhorada do CAL3QHC, o modelo CAL3QHCR, apesar de esse modelo não ter passado por revisões e análises como ocorreu com seu precursor (ECKHOFF; BRAVERMAN, 1995).

Assim, este trabalho teve como objetivo aplicar o modelo numérico CAL3QHCR e avaliar seu desempenho em um estudo de dispersão atmosférica de material particulado $\left(\mathrm{MP}_{10}\right.$ e $\left.\mathrm{MP}_{2,5}\right)$ emitido por fontes veiculares em uma microrregião localizada no centro do município de Belo Horizonte (MG).

\section{Modelos de dispersão de poluentes veiculares}

O modelo de dispersão da pluma gaussiana é o método mais utilizado e confiável para calcular as concentrações de poluentes no ar com base nas condições atmosféricas (GODISH, 1997). No modelo gaussiano, a emissão de uma fonte pontual espalha-se na atmosfera sob a forma de uma pluma que possui as mesmas características da curva normal usada em estatística (MEDEIROS, 2003).

Entre os modelos gaussianos utilizados para prever os impactos originados por emissões veiculares na qualidade do ar de regiões localizadas no entorno de vias de tráfego têm-se o CALINE3, o CAL3QHC e o CAL3QHCR, os quais são descritos a seguir.

\section{California Line Source - 3}

Esse modelo é a terceira geração do modelo de dispersão California Line Source (CALINE) desenvolvido pelo Departamento de Transportes da Califórnia. É baseado no modelo gaussiano de difusão e emprega o conceito de zona de mistura inicial para caracterizar a dispersão dos poluentes emitidos por veículos em movimento em uma via de tráfego (BENSON, 1979).

Os principais dados de entrada do modelo são: dados meteorológi$\cos ^{1}$ (velocidade e direção do vento, estabilidade atmosférica, temperatura); rugosidade da superfície (uniforme para toda a área de estudo); velocidades de absorção e deposição do poluente no solo; largura, altura e volume de tráfego horário de cada via de tráfego; fator de emissão do poluente; e as coordenadas dos receptores. Com esses dados, o modelo é 
capaz de prever concentrações de poluentes (CO, MP, gases inertes) em um raio de $150 \mathrm{~m}$ da via de tráfego (BENSON, 1979).

O modelo CALINE3 divide as vias de tráfego em segmentos (links) que possuem largura, altura, volume de tráfego e emissões veiculares constantes, utilizando no máximo 20 links e 20 receptores discretos. A concentração total medida no receptor é calculada usando-se a seguinte equação:

$C(x, y)=\frac{Q}{\pi \cdot n_{z} \cdot u} \int_{y_{1}-y}^{y_{2}-y} \exp \left(-\frac{y^{2}}{2 n_{y}^{2}}\right) d y$

Equação 1

Onde:

Q: taxa de emissão linear (g/m.s);

$u$ : velocidade do vento $(\mathrm{m} / \mathrm{s})$;

$\sigma_{\mathrm{y}}$ e $\sigma_{\mathrm{z}}$ : coeficientes de dispersão horizontal e vertical, respectivamente $(\mathrm{m})$;

x: distância do receptor na direção do vento (m);

y: distância do receptor na direção oposta ao vento (m);

$y_{1}$ e $y_{2}$ : coordenadas y finais dos elementos finitos (BENSON, 1979).

\section{California Line Source for Queuing \& Hot Spot Calculations}

O modelo CAL3QHC utiliza o processo de dispersão gaussiano para estimar as concentrações de poluentes atmosféricos (CO e MP) ao longo das vias de tráfego para veículos em movimento e veículos parados nos cruzamentos sinalizados. Inclui um algoritmo que considera o comprimento de filas formadas por veículos parados nos cruzamentos sinalizados e utiliza o modelo CALINE3 para fazer os cálculos de dispersão (USEPA, 1992a).

O CAL3QHC utiliza os mesmos dados de entrada do CALINE3 relativos à geometria da via de tráfego, dados meteorológicos, localização de receptores e taxas de emissão. A esses dados são acrescentados a taxa de emissão do veículo parado, o tempo do ciclo semafórico (incluindo cada fase) e as informações das intersecções a serem modeladas (número de pistas, taxa de saturação, entre outros). Esse modelo utiliza dois tipos de links: free flow link, que representa os segmentos de via não sinalizados, com fluxo livre; e queue link, que representa os segmentos de via sinalizados. Permite o uso de 120 links e 60 receptores discretos, sendo capaz de processar uma hora de dados ${ }^{2}$.

\section{CAL3QHC-Refined}

Esse modelo é a versão estendida do CAL3QHC, o qual permite processar até um ano de dados meteorológicos horários (dados MET), tais como velocidade e direção dos ventos, classe de estabilidade, altura da camada de mistura, bem como utilizar dados de emissão veicular, tráfego e sinalização (dados ETS) mais detalhados
(ECKHOFF; BRAVERMAN, 1995). Assim como o seu precursor, utiliza o modelo CALINE3 para fazer os cálculos de dispersão de acordo com a Equação 1.

O CAL3QHCR disponibiliza duas aproximações:

- aproximação I: utiliza até um ano de dados MET e uma hora "padrão" de dados ETS;

- aproximação II: utiliza os mesmos dados MET da aproximação I, mas os dados ETS são mais detalhados, representando as condições de tráfego para cada hora dos sete dias da semana, gerando uma "semana padrão" ( 7 x 24 horas)

Para esse modelo, a concentração máxima de CO é calculada em 1 hora ou em 8 horas, e a concentração máxima de MP é calculada em 24 horas, conforme a legislação.

\section{Metodologia}

\section{Definição da região de estudo}

O presente estudo foi delimitado a uma microrregião localizada na região central de Belo Horizonte. Os principias critérios para seleção dessa área em particular foram:

- a microrregião escolhida situa-se na área central de Belo Horizonte (Figura 1), sendo uma das regiões críticas do município em relação ao tráfego de veículos, conforme informação fornecida pela Empresa de Transportes de Belo Horizonte (BHTRANS);

- a microrregião apresenta baixa influência de poluição industrial;

- $\quad$ existência de dados MET e ETS representativos;

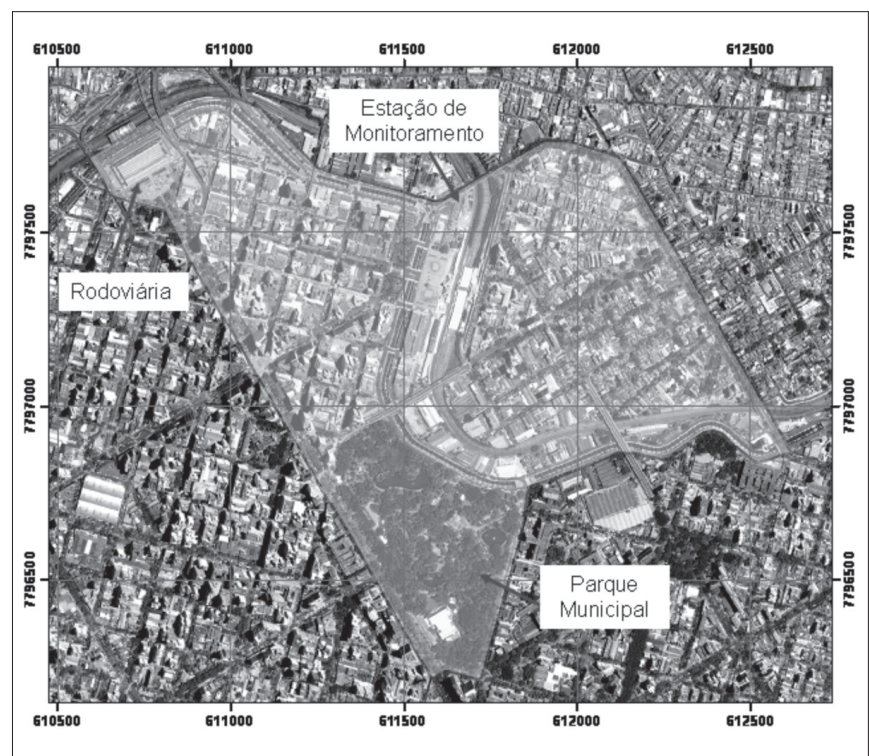

Figura 1 - Contorno que define a microrregião do estudo (GOOGLE MAPS, 2009).

${ }^{2}$ A nova versão do modelo CAL3QHC adquirida em 25/09/2008 permite o uso de 600 links. 
- $\quad$ existência de uma estação de monitoramento da qualidade do ar, localizada na praça Rui Barbosa, onde poderiam ser instalados os equipamentos complementares de amostragem. Essa estação está localizada em uma região que possui intenso tráfego de veículos.

\section{Seleção do modelo}

A utilização do modelo de dispersão CAL3QHCR baseou-se nas seguintes premissas:

- a região analisada apresenta tráfego intenso com constantes formações de engarrafamentos;

- nessa região, o fluxo de veículos varia consideravelmente ao longo de um dia e de uma semana;

- um estudo adequado da qualidade do ar nessa região requer a aplicação de informações para períodos superiores a uma hora.

\section{Cenários analisados}

As simulações numéricas realizadas na primeira parte deste estudo utilizaram 119 links e um receptor discreto - RCP - (Figura 2). Quatro cenários distintos foram analisados:

- o primeiro corresponde ao estudo da dispersão do poluente $\mathrm{MP}_{10}$ com o uso da aproximação I;

- $\quad$ o segundo corresponde à simulação do poluente $\mathrm{MP}_{10}$ com o uso da aproximação II;
- $\quad$ o terceiro corresponde à simulação do poluente $\mathrm{MP}_{2,5}$ com o uso da aproximação I;

- $\quad$ o quarto corresponde à simulação do poluente $\mathrm{MP}_{2,5}$, com o uso da aproximação II.

Os dados ETS utilizados variaram em função do tipo de poluente $\left(\mathrm{MP}_{10}\right.$ ou $\left.\mathrm{MP}_{2,5}\right)$ e do tipo de aproximação (I ou II). Os demais dados de entrada não variaram (links, rugosidade da superfície etc.).

$\mathrm{Na}$ segunda parte das simulações, foram geradas isolinhas de concentração de poluentes na atmosfera e, para tal, foram utilizados os quatro cenários supracitados e uma malha de receptores representados pelos cruzamentos das linhas verticais e horizontais da Figura 2.

\section{Obtenções dos dados}

\section{Dados meteorológicos}

O modelo CAL3QHCR é programado para trabalhar com até um ano completo de dados meteorológicos, sendo fundamental que as informações meteorológicas adquiridas representem adequadamente as condições da região de estudo. Os dados meteorológicos utilizados foram fornecidos pela Estação Meteorológica do Centro de Desenvolvimento da Tecnologia Nuclear (CDTN), localizada a uma distância de aproximadamente $6 \mathrm{~km}$ da área de estudo.

Os dados MET utilizados neste estudo correspondem ao período de 16 de fevereiro de 2008 a 28 de março de 2008, sendo: velocidade

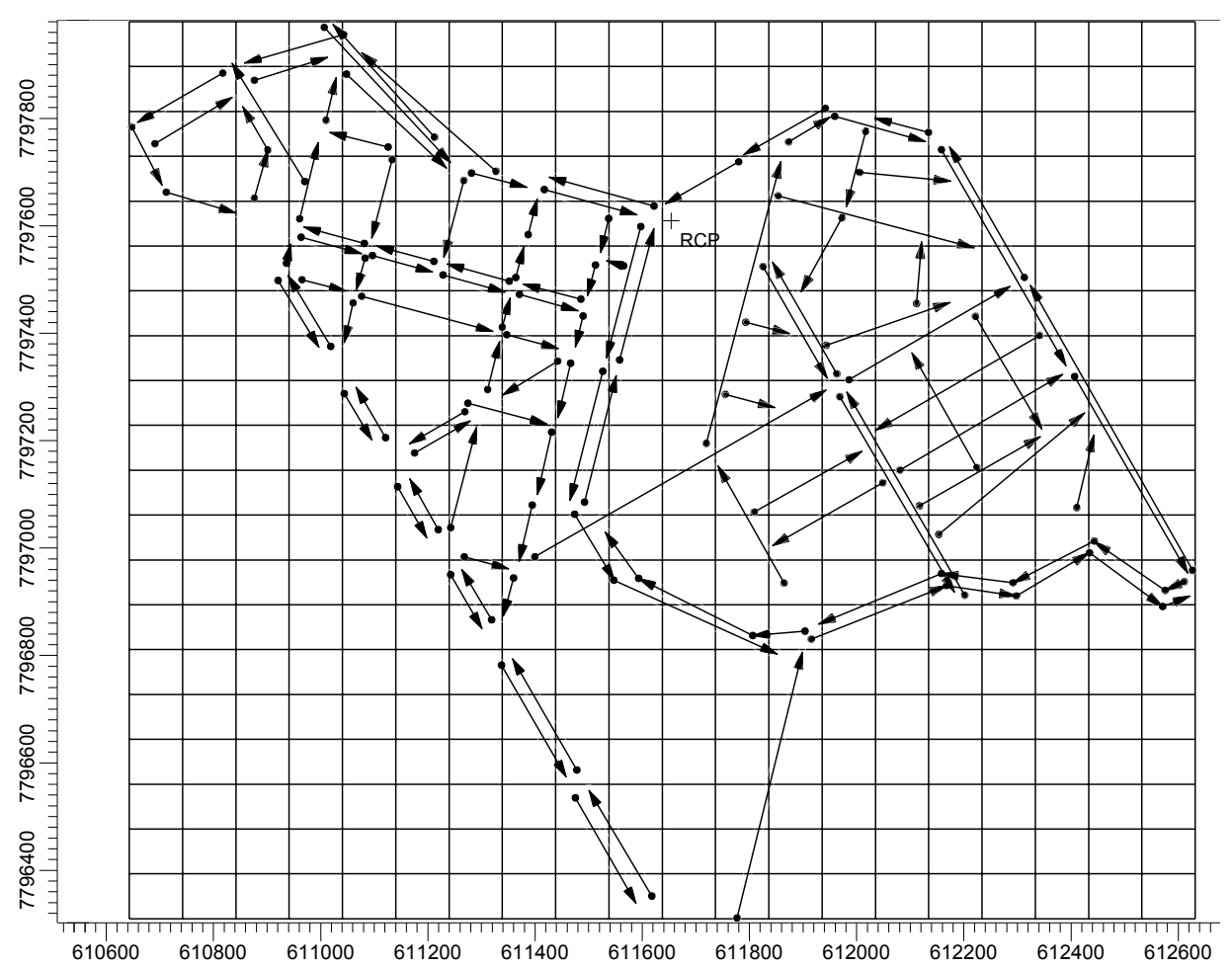

Figura 2 - Área de trabalho do modelo CAL3QHCR - links, receptor discreto (RCP) e malha de receptores. 
e direção dos ventos, temperatura, camada de mistura e estabilidade atmosférica. A estabilidade atmosférica foi baseada nas informações de vento (velocidade, direção e desvio padrão da direção) medidas nessa Estação, e a altura da camada de mistura foi calculada a partir das informações de temperatura e umidade relativa.

Foi observada a predominância absoluta $(57,54 \%)$ de ventos da classe de velocidade $1(0,5 \mathrm{~m} / \mathrm{s}<\mathrm{u}<2,1 \mathrm{~m} / \mathrm{s})$. O percentual de ventos calmos foi de aproximadamente 7\%. Praticamente não ocorreram ventos acima de 5,7 m/s. Essa condição dos ventos foi favorável, pois o modelo CALQ3HCR não apresenta bons resultados para ventos fortes (ECKHOFF; BRAVERMAN, 1995). Em relação à direção do vento, houve predominância de vento soprando da direção leste (ENE;E;ESE).

A aplicação do modelo CALQ3HCR é indicada, preferencialmente, para condições atmosféricas estáveis ou neutras. No período analisado, houve predominância da classe D - condição de estabilidade atmosférica neutra.

Outro fator importante na estimativa da concentração de poluentes atmosféricos é a altura da camada de mistura (ACM). Uma das formas de se avaliar o topo da camada de mistura é por meio da utilização dos perfis de temperatura e umidade obtidos por radiossondagem (STULL, 1988). Entretanto, como a cidade de Belo Horizonte não possui registros de equipamentos de radiossondagem, utilizou-se o nível de convecção livre (NCL) como aproximação da altura da camada de mistura.

O NCL é usado para estimar a ACM entre a superfície e a base da inversão (SEIBERT et al., 2000), sendo obtido por meio de uma equação empírica dada por:

$N C L=110\left(t-t_{d}\right)$

Equação 2

Onde:

$t$ : temperatura do ar $\left({ }^{\circ} \mathrm{C}\right)$;

$t_{\mathrm{d}}$ : temperatura do ponto de orvalho $\left({ }^{\circ} \mathrm{C}\right)$, a qual é dada por:

$t_{d}=\frac{(116,9+237,3 \ln e)}{(16,78-\ln e)}$

Equação 3

Onde:

$e=\frac{U R}{100} 0,611 \exp \left(\frac{17,27 T}{T+237,3}\right)$

Equação 4

UR: umidade relativa do ar (\%).

No presente estudo, foram utilizados valores de ACM que variaram de 1.742 a $117 \mathrm{~m}$ (valor médio $=623 \mathrm{~m}$ ) para o período considerado

\section{Dados de volume de tráfego e sinalização}

Diversas informações são necessárias para que cada trecho das vias selecionadas (link) possa ser representado adequadamente no modelo CAL3QHCR.

Os dados de volume de tráfego e sinalização para cada via da microrregião estudada foram fornecidos pela BHTRANS. Inicialmente, selecionaram-se as informações relevantes referentes à região estudada. Em seguida, constatou-se a existência de lacunas no banco de dados, ou seja, não havia informações de volume para todas as vias da região em estudo. Sendo assim, foi preciso estimar o volume de tráfego das vias que não possuíam essa informação. As lacunas existentes no banco de dados de volume foram preenchidas utilizando-se o conhecimento do trânsito dessa região e adotando-se o princípio de conservação do fluxo.

\section{Fatores de emissão}

As concentrações de poluentes na atmosfera são influenciadas diretamente pelos fatores de emissão (FE) desses poluentes. O modelo CAL3QHCR utiliza taxas de emissão de poluentes distintas para os dois tipos de links (free flow link e queue link). Dessa forma, dois tipos de fatores de emissão veicular são considerados: o fator de emissão para os veículos em movimento, medido em $\mathrm{g} / \mathrm{km}$, e o fator de emissão para os veículos parados, medido em g/h. O FE utilizado nas simulações é um fator de emissão composto, que considera o fator de emissão para os diferentes tipos de combustível (diesel, gasolina e álcool).

Para os veículos em movimento, foram utilizados os FE recomendados pela Companhia de Tecnologia de Saneamento Ambiental (CETESB). Embora os FE da CETESB considerem apenas veículos novos (motores do ciclo Otto - movidos a gasolina, álcool ou suas misturas e gás natural e motores do ciclo Diesel - movidos a diesel) e sejam determinados a partir de ensaios realizados sob condições controladas de laboratório, eles são os mais condizentes com a frota de veículos nacional e, portanto, os mais adequados para serem adotados neste estudo.

Assim, os FE considerados nas simulações do CAL3QHCR foram $0,047 \mathrm{~g} / \mathrm{km}$ para o $\mathrm{MP}_{10}$ e $0,029 \mathrm{~g} / \mathrm{km}$ para o $\mathrm{MP}_{2,5}$ (CETESB, 2008). No Brasil, não existem registros oficiais sobre a medição dos fatores de emissão para veículos parados ${ }^{3}$. Portanto, foram utilizados os dados disponibilizados pela USEPA (1998), os quais correspondem a 2,59 g/h para o $\mathrm{MP}_{10}$ e 1,00 g/h para o $\mathrm{MP}_{2,5}$

\section{Medida da concentração de material particulado}

A determinação da concentração de material particulado fino $\left(\mathrm{MP}_{2,5}\right)$ e grosso $\left(\mathrm{MP}_{10}\right)$ na atmosfera foi realizada utilizando-se um analisador de ar Partisol Modelo 2000-D dicotômico, o qual foi instalado na estação de monitoramento da qualidade do ar localizada na

${ }^{3}$ De acordo com informações fornecidas por técnicos da CETESB diretamente aos pesquisadores. 
região de estudo. As amostragens foram realizadas no período de 16 de fevereiro a 28 de março de 2008.

No analisador dicotômico, o ar é coletado por um receptáculo a uma vazão de $16,7 \mathrm{~L} /$ minuto, onde é realizada a separação do $\mathrm{MP}_{10}$. Um impactor virtual ("divisor dicotômico"), situado após o receptáculo, possui dois controladores de vazão. Uma corrente de $\operatorname{ar}\left(\mathrm{MP}_{10}\right)$, com uma vazão de 1,7 L/minuto, segue em direção a um ponto coletor, onde o $\mathrm{MP}_{10}$ é depositado em um filtro de quartzo. Uma segunda corrente, com uma vazão de $15 \mathrm{~L} /$ minuto, separa as partículas que possuem diâmetro menor que 2,5 $\mu \mathrm{m}\left(\mathrm{MP}_{2,5}\right)$, que são depositadas em um filtro de Teflon ${ }^{\circledR}$ (THERMO ELECTRON CORPORATION, 2006).

Antes da amostragem, os filtros limpos ("brancos"), foram pesados utilizando-se uma balança digital. Antes de cada pesagem, os filtros permaneceram por 24 horas em um dessecador composto de prateleiras treliçadas, possuindo em sua base uma bandeja coberta de sílica-gel. A sílica-gel, antes de ser depositada no dessecador, foi submetida a um aquecimento $\left(110^{\circ} \mathrm{C}\right)$ por 24 horas para garantir a retirada total da umidade. Transcorrido o período de secagem, a sílica foi transferida para o dessecador. Tais procedimentos foram realizados em um laboratório com ambiente controlado: temperatura de $23^{\circ} \mathrm{C}$, umidade média de $50 \%$ e desvios máximos de $10 \%$. Na sequência, os filtros foram levados para amostragem. Depois de amostrados, foram embalados, identificados e retornaram para a dessecagem e pesagem.

A concentração do MP foi calculada de acordo com a Equação 5:

$C=\frac{m_{f}-m_{0}}{V o l}$

Equação 5

Onde:

$\mathrm{m}_{0}$ : massa do filtro limpo (massa inicial);

$\mathrm{m}_{\mathrm{f}}$ : massa do filtro amostrado (massa final);

Vol: volume de ar que passa pelo equipamento durante o período de amostragem.

\section{Tratamento dos dados}

Os resultados obtidos por meio das simulações numéricas foram confrontados com os dados amostrados na estação da praça Rui Barbosa. Essa comparação foi realizada por meio de uma ferramenta estatística, a qual possibilita avaliar o desempenho do modelo na determinação da concentração diária média de cada um dos poluentes considerados.

Existem vários parâmetros estatísticos para comparar os valores previstos $\left(C_{p}\right)$ com os observados $\left(C_{o}\right)$. Esses parâmetros servem para avaliar o quanto o modelo está "sub" ou "super" estimando os valores observados. Por recomendação da USEPA (1992b), o parâmetro utilizado neste trabalho para fazer esse tipo de comparação é o Fractional Bias (FB):
$\mathrm{FB}=\frac{\left(\overline{\mathrm{C}}_{\mathrm{p}}-\overline{\mathrm{C}}_{\mathrm{o}}\right)}{0,5 \cdot\left(\overline{\mathrm{C}}_{\mathrm{p}}+\overline{\mathrm{C}}_{\mathrm{o}}\right)} \quad,-2<\mathrm{FB}<+2$

Equação 6

Onde:

$\bar{C}_{p}$ : média de todas as concentrações previstas;

$\bar{C}_{o}$ : média de todas as concentrações observadas.

O FB é um fator adimensional, simétrico e limitado entre os valores de -2 e +2 . Valores de FB iguais a -2 indicam que o modelo está subestimando ao máximo os valores observados, e valores de FB iguais à +2 indicam que o modelo está superestimando ao máximo os valores observados. $\mathrm{FB}= \pm 0,67$ significa que a concentração prevista é o dobro ou a metade da concentração observada (COX; TIKVART, 1990).

\section{Resultados e discussões}

\section{Curvas de concentração}

As curvas de concentração previstas pelo modelo foram obtidas para um receptor discreto $(\mathrm{X}, \mathrm{Y}, \mathrm{Z})$, localizado na mesma posição onde foram coletados os dados de concentração de MP pelo analisador dicotômico. O objetivo desta análise foi verificar a correspondência entre as concentrações previstas na simulação numérica e as concentrações observadas.

Uma análise das curvas representadas na Figura 3 evidencia que as concentrações de $\mathrm{MP}_{10}$ e $\mathrm{MP}_{2,5}$ previstas pela simulação numérica foram menores do que as concentrações de $\mathrm{MP}_{10}$ e $\mathrm{MP}_{2,5}$ observadas experimentalmente. A análise estatística utilizando o fator FB comprova esse resultado - Cenário $1: \mathrm{FB}=-1,38$; Cenário 2: $\mathrm{FB}=-1,38$; Cenário 3: $\mathrm{FB}=-1,51$; Cenário 4: $\mathrm{FB}=-1,74$.

Considerando-se que as concentrações de poluentes previstas são diretamente proporcionais ao fator de emissão do veículo, uma possível explicação para esse resultado seria a utilização de FE que não correspondem aos valores reais. No Brasil, há uma carência de pesquisas na área de emissão veicular, sendo que a única fonte registrada é a CETESB. Esta, por sua vez, utiliza fatores de emissão que não são necessariamente condizentes com a realidade da frota de Belo Horizonte. De acordo com Osses, Dursbeck e Corvalán (2001), os modelos de emissão de poluentes emitidos por fontes móveis (veículos), em áreas urbanas, requerem uma informação detalhada que descreva a atividade do tráfego na área de estudo. Um adequado processamento dessa informação permite calcular as emissões associadas com a atividade do transporte, utilizando-se FE que permitem conhecer a massa do poluente por quilômetro percorrido $(\mathrm{g} / \mathrm{km})$, a partir do tipo de veículo, e a velocidade média do percurso para as diferentes categorias veiculares. 
É importante destacar que os FE utilizados nas simulações referem-se apenas às emissões liberadas pelo escapamento do veículo. No entanto, sabe-se que as concentrações observadas recebem a contribuição de diversas fontes que liberam MP para a atmosfera, como a ressuspensão de poeiras, o desgaste de pneus, pastilhas e lonas de freios dos veículos (SILVA, 2007). Nesse caso, o uso de modelos receptores permitiria estimar a contribuição percentual de cada uma das fontes poluidoras da atmosfera e, portanto, corrigir os resultados das concentrações medidas. A aplicação do modelo receptor (QUEIROZ, 2006) ao MP coletado nas amostragens revelaria qual o percentual de MP que é proveniente especificamente das emissões veiculares.

Outro aspecto relevante para as diferenças entre as concentrações previstas e as observadas refere-se ao fato de que o modelo não leva em consideração a existência de barreiras físicas existentes ao longo dos links, devido à arquitetura urbana (prédios, casas ou árvores). Por não considerar topografias complexas, o modelo CAL3QHCR não leva em consideração os processos de dispersão causados por essas barreiras, que formam túneis de vento e alteram a forma de transporte dos poluentes na atmosfera.

Estudos realizados na Índia, com o objetivo de avaliar o desempenho de diferentes modelos de dispersão veiculares (CALINE3, M-GFLSM e CAL3QHC), indicaram que o modelo CAL3QHC foi o que gerou melhores resultados nas previsões das concentrações de $\mathrm{MP}_{10}$ e $\mathrm{MP}_{2,5}$ nas proximidades das vias de tráfego. O cenário considerado constituiu-se em um único cruzamento composto por duas vias de tráfego, que foram subdivididas em seis links (GOKHALE; RAOKHANDE, 2008), condições muito simples quando comparadas às adotadas no presente trabalho. A comparação entre as curvas de concentrações previstas e observadas apresentou grande semelhança. Entretanto, as características do cruzamento estudado na Índia diferem-se significativamente das características da microrregião estudada em Belo Horizonte - topografia plana, pouca influência da arquitetura urbana nos processos de dispersão e pequena quantidade de veículos a diesel que compõem a frota local. Mesmo tendo encontrado resultados satisfatórios, Gokhale e Raokhande (2008) também atribuem as pequenas diferenças entre $C_{\mathrm{p}}$ e $C_{\mathrm{o}}$ aos fatores de emissão, os quais deveriam ser mais condizentes com a frota local.

Observando-se as curvas de concentração da Figura 3, é possível verificar que os resultados de concentração previstos para as aproximações I e II são semelhantes. A diferença entre estas duas aproximações refere-se aos dados de tráfego e sinalização. Esse resultado foi inesperado, pois a aproximação II utiliza dados de volume de tráfego e sinalização mais detalhados e próximos das condições reais de tráfego.

Uma análise de sensibilidade para esses parâmetros revelou que as concentrações de poluentes previstas são pouco influenciadas pelo volume de tráfego. No entanto, o aumento do tempo de sinal vermelho contribuiu para o aumento das concentrações previstas, uma vez que a intensidade de engarrafamentos aumentou

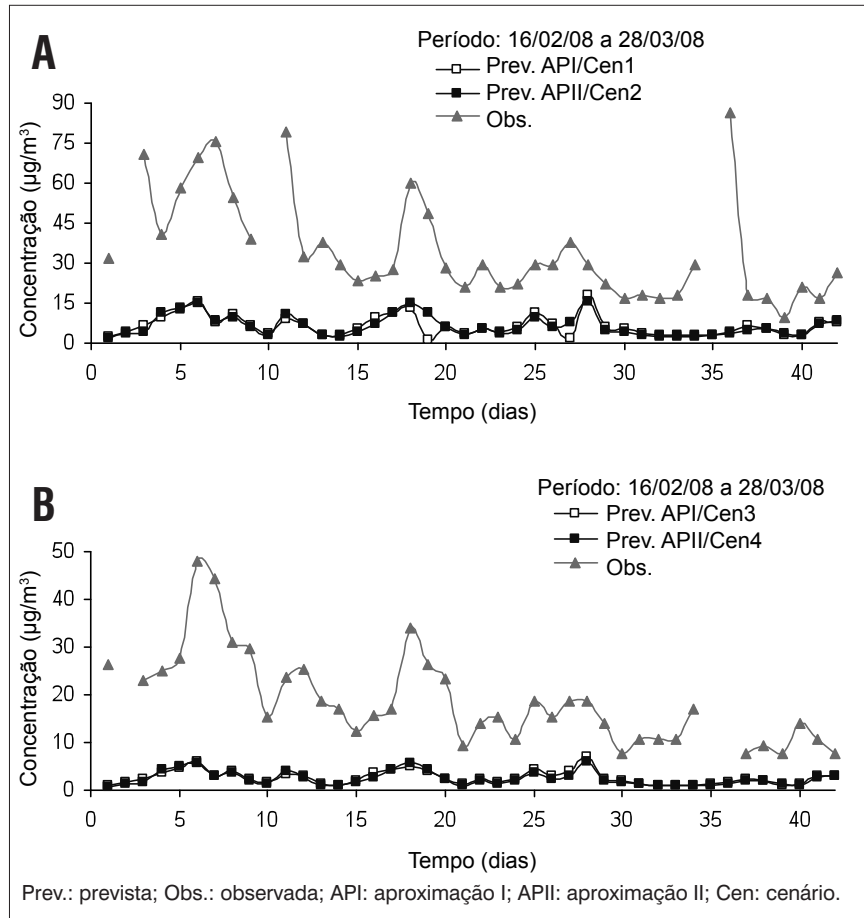

Figura 3 - a) curvas de concentrações de $\mathrm{MP}_{10}$ previstas e observada - cenários 1 e 2; b) curvas de concentrações de $\mathrm{MP}_{2,5}$ previstas e observada - cenários 3 e 4.

concomitantemente. Portanto, a semelhança entre as duas aproximações indica que o algoritmo utilizado pelo modelo CAL3QHCR para estimar os engarrafamentos das vias de tráfego pode estar subestimando a realidade do trânsito nas grandes metrópoles do Brasil. A existência de uma infraestrutura de trânsito mais precária, a idade mais avançada da frota e o elevado índice de acidentes contribuem para a ocorrência de engarrafamentos mais frequentes e intensos nos países em desenvolvimento, quando comparados com os países desenvolvidos.

\section{Isolinhas de concentração}

As isolinhas de concentração geradas pelo CAL3QHCR para o $\mathrm{MP}_{10}$ são apresentadas na Figura 4. De acordo com os índices de qualidade do ar (IQAr) propostos pela CETESB (2008), para concentrações entre 0 e $50 \mu \mathrm{g} / \mathrm{m}^{3}$, a qualidade do ar é considerada boa; entre 50 e $150 \mu \mathrm{g} / \mathrm{m}^{3}$, regular; entre 150 e $250 \mu \mathrm{g} / \mathrm{m}^{3}$, inadequada; entre 250 e $420 \mu \mathrm{g} / \mathrm{m}^{3}$, MÁ; e para concentrações $>420 \mu \mathrm{g} / \mathrm{m}^{3}$, péssima. As isolinhas de concentração de $\mathrm{MP}_{10}$ para máximo em 24 horas indicam que a qualidade do ar é boa (0 a $\left.50 \mu \mathrm{g} / \mathrm{m}^{3}\right)$ na maior parte da microrregião, mas existem áreas onde a qualidade do ar varia de regular a péssima, com concentrações que estão muito acima do padrão de qualidade do $\operatorname{ar}\left(150 \mu \mathrm{g} / \mathrm{m}^{3}\right): 2.315 \mu \mathrm{g} / \mathrm{m}^{3}$ para a aproximação I e mais de $5.000 \mu \mathrm{g} / \mathrm{m}^{3}$ para a aproximação II.

A ausência de padrões de qualidade do ar para o $\mathrm{MP}_{2,5}$ no Brasil impossibilita a existência de IQAr para esse poluente Portanto, 
foram utilizados os índices de qualidade do ar adotados pela Agência Ambiental dos Estados Unidos, ajustados às cores e às classificações adotadas para o MP 10 pela CETESB (USEPA, 1999; CETESB, 2008).

As isolinhas de concentração para o $\mathrm{MP}_{2,5}$ são apresentadas na Figura 5. Para concentrações entre 0 e $15 \mu \mathrm{g} / \mathrm{m}^{3}$, a qualidade do ar é considerada boa; entre 15 e $65 \mu \mathrm{g} / \mathrm{m}^{3}$, regular; entre 65 e $150 \mu \mathrm{g} /$ $\mathrm{m}^{3}$, inadequada; entre 150 e $250 \mu \mathrm{g} / \mathrm{m}^{3}$, má; e para concentrações > $250 \mu \mathrm{g} / \mathrm{m}^{3}$, péssima. As isolinhas de concentração de $\mathrm{MP}_{2,5}$ para máximo em 24 horas mostradas na Figura 5 indicam que a qualidade do ar é boa ( 0 a $\left.15 \mu \mathrm{g} / \mathrm{m}^{3}\right)$ em quase toda a microrregião, mas existem áreas onde a qualidade do ar varia de regular à má, com concentrações atingindo $28 \mu \mathrm{g} / \mathrm{m}^{3}$ para a aproximação I e $215 \mu \mathrm{g} / \mathrm{m}^{3}$ para a aproximação II, sendo que esta encontra-se acima dos padrões da USEPA $\left(35 \mu \mathrm{g} / \mathrm{m}^{3}\right)$.

Os locais onde a qualidade do ar variou de regular à péssima correspondem a uma região de vales, com topografias mais baixas

\section{A}
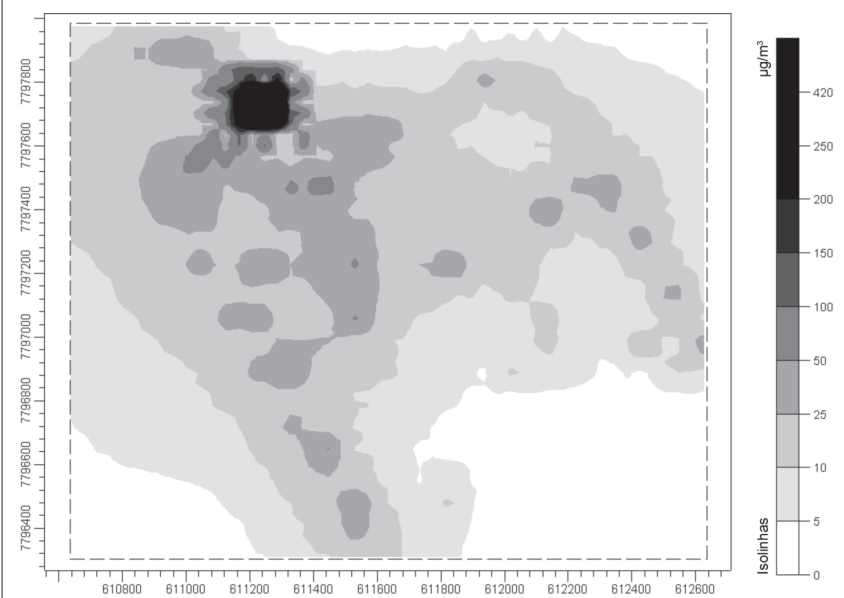

B

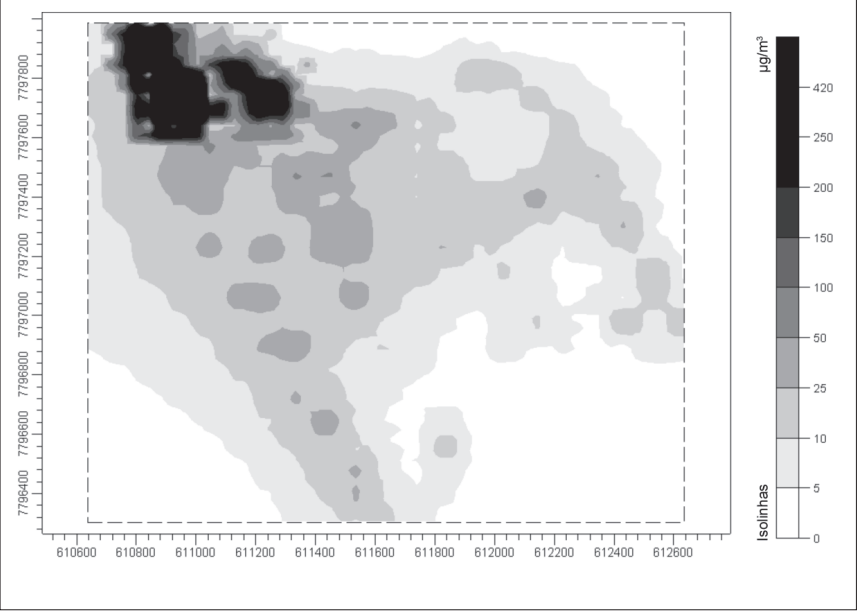

Figura 4 - a) isolinhas de concentração de $M P_{10}$, expressas em $\mu \mathrm{g} / \mathrm{m}^{3}$, para máximo em 24 horas - cenário 1; b) isolinhas de concentração de $\mathrm{MP}_{10}$ para máximo em 24 horas - cenário 2. em relação às áreas vizinhas. A presença dessas depressões aumenta o tempo de residência dos poluentes nessas áreas, o que dificulta o processo de dispersão, acarretando um aumento nos níveis de concentração de poluentes. Pode-se verificar que nesses vales existe uma canalização do fluxo de poluentes da região a montante para a região a jusante, visto que a direção predominante do vento durante o período estudado ocorreu no sentido leste-oeste. Particularmente nos locais que apresentaram maior concentração de poluentes, o tráfego de veículos é intenso, em especial o tráfego de veículos a diesel (ônibus).

Conforme se pode observar, as isolinhas de concentração estão coerentes com os dados de topografia (altura dos links), dados meteorológicos (vento) e dados de volume de tráfego e sinalização. Entretanto, a escala de concentrações provavelmente não está adequada, pois os fatores de emissão e o algoritmo utilizado pelo modelo para estimar os engarrafamentos das vias de tráfego pode estar subestimando a realidade do trânsito da região.

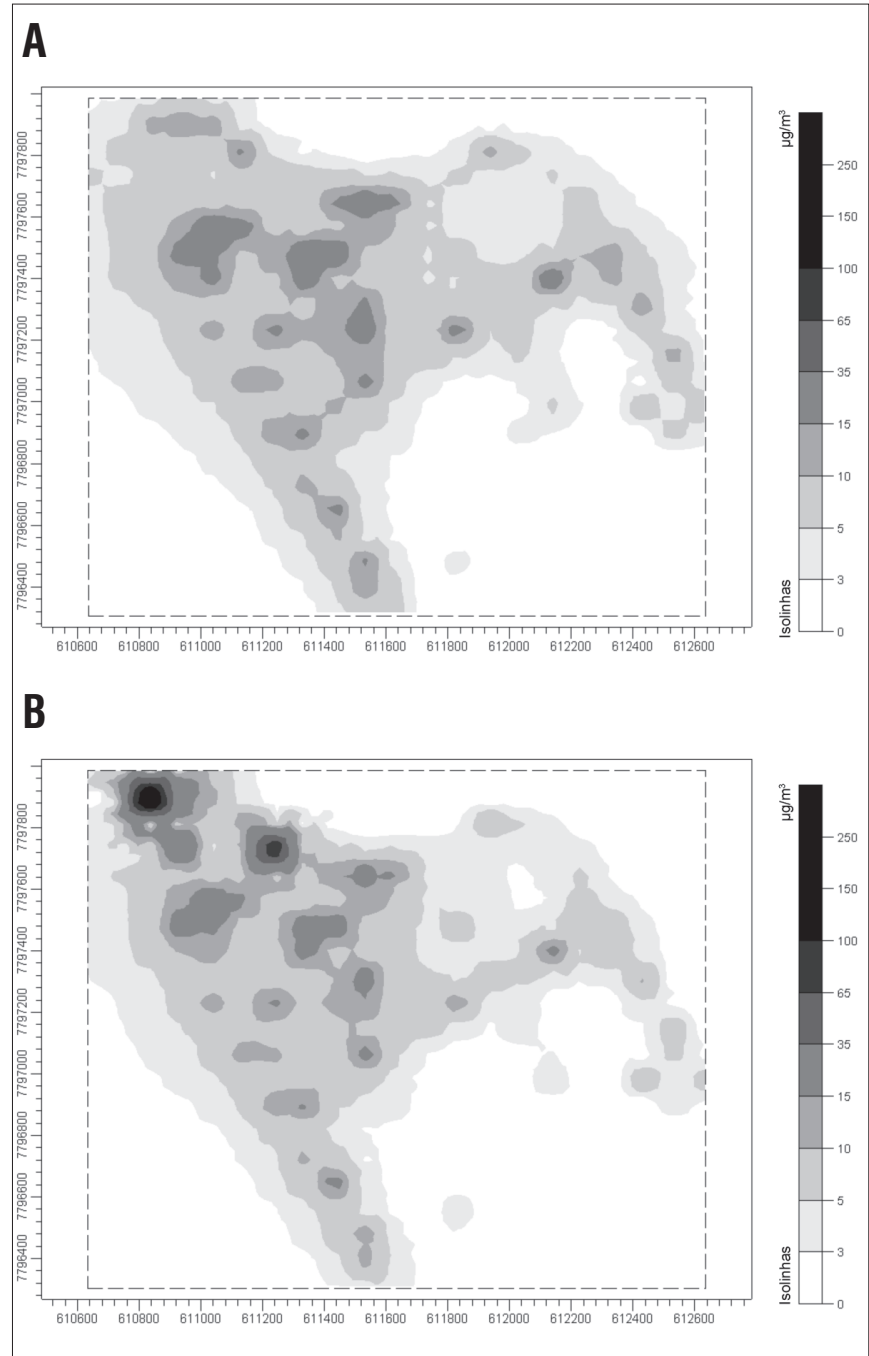

Figura 5 - a) isolinhas de concentração de $\mathrm{MP}_{25}$ expressas em $\mu \mathrm{g} / \mathrm{m}^{3}$, para máximo em 24 horas - cenário 3; b) isolinhas de concentração de $\mathrm{MP}_{25}$ para máximo em 24 horas - cenário 4. 


\section{Conclusões}

O estudo realizado neste trabalho revelou que as concentrações de $\mathrm{MP}_{2,5}$ e $\mathrm{MP}_{10}$ previstas nas simulações foram menores do que as concentrações observadas experimentalmente. Uma análise de sensibilidade realizada com o CAL3QHCR demonstrou que o fator de emissão é o parâmetro que exerce maior influência nas concentrações previstas. Este, por sua vez, depende das características da frota e de sua manutenção, do tipo do motor e tecnologia adotada, do tipo e qualidade do combustível, do sistema viário e do modo de operação do veículo. Evidentemente, essas diferenças podem comprometer estudos realizados com valores de fatores de emissão obtidos para realidades distintas. Assim, considerando-se que os fatores de emissão utilizados neste estudo não se aplicam diretamente às características da frota de Belo Horizonte, é razoável que exista uma discrepância entre as concentrações previstas e as observadas.

Evidentemente, a avaliação dos fatores de emissão - levando-se em conta as condições específicas da frota de veículos do município de Belo Horizonte, conforme metodologia proposta por outros autores, como, por exemplo, a utilizada por Sánchez-Ccoyllo et al. (2009) em São Paulo - é importante não apenas para a realização de estudos local e regional de avaliação da qualidade do ar por meio de simulação numérica, mas também para o estabelecimento de políticas públicas que contribuam para a melhoria da qualidade ambiental e, portanto, para a saúde da população.

Outro ponto importante, que pode explicar as diferenças entre os valores de concentração previstos e observados, é a dificuldade em se considerar uma topografia complexa no modelo CAL3QHCR. Essa característica do modelo pode interferir na avaliação de processos de dispersão causados pela arquitetura urbana, que formam túneis de vento e alteram os níveis de concentração de poluentes na atmosfera.

Mesmo subestimando as concentrações, a realização da modelagem com o CAL3QHCR revelou que existem locais da microrregião analisada onde a qualidade do ar apresenta-se de regular à péssima. Esses pontos correspondem à região de vales onde o tráfego de veículos é intenso, em especial o tráfego de veículos a diesel (ônibus), que são os principais emissores de MP para a atmosfera.

Os resultados aqui obtidos demonstram que a realização de estudos com o modelo CAL3QHCR para avaliação da qualidade do ar em grandes metrópoles implica na consideração de um grande número de links. Essa situação pode acarretar a elaboração de um banco de dados de entrada extenso e de difícil formatação. Assim, a aplicação desse modelo em grandes áreas, com numerosas vias, é limitada pela existência de informações de tráfego. Portanto, a formação de um banco de dados de volume de tráfego pela BHTRANS é fundamental não somente para a organização do trânsito da cidade, mas também para o estudo e controle da qualidade do ar.

\section{Agradecimentos}

Os autores agradecem à Fundação Estadual do Meio Ambiente (FEAM), pelo apoio e incentivo dados a este trabalho, à Empresa de Transportes e Trânsito de Belo Horizonte (BHTRANS), em especial a Márcio Cerqueira Batitucci, pelo fornecimento dos dados de volume de tráfego e sinalização, e à Fundação de Amparo à Pesquisa do Estado de Minas Gerais (FAPEMIG) pelo suporte financeiro do projeto (processo $n^{\circ}$ TEC-579-06).

\section{Referências}

BENSON, P.E. CALINE3 - A versatile dispersion model for predicting air pollutant levels near highways and arterial streets. Abridged version by computer science corporations. Report No. FHWA/CA/TL-79/23, Interim report, November 1979.

COMPANHIA DE TECNOLOGIA DE SANEAMENTO AMBIENTAL (CETESB). Relatório de Qualidade do Ar no Estado de São Paulo 2007. São Paulo: Companhia de Tecnologia de Saneamento Ambiental, 2008.

CONSELHO NACIONAL DE MEIO AMBIENTE (CONAMA). Resolução $n^{\circ}$ 003, de 28 de junho de 1990: dispõe sobre padrões de qualidade do ar, previstos no PRONAR. Diário Oficial da União, Brasília, DF, 22 ago. 1990.

COX, W. M.; TIKVART, J. A. A statistical procedure for determining the best performing air quality simulation model. Atmospheric Environment, v. 24A, n. 9, p. 2387-2395, 1990.

ECKHOFF, P. A.; BRAVERMAN, T. N. Addendum to the User's Guide to CAL3QHC Version 2.0 (CAL3QHCR USER'S GUIDE). U.S. Environmental
Protection Agency. Office of Air Quality Planning and Standards Technical Support Division. Research Triangle Park, North Carolina, September, 1995.

GODISH, T. Air quality. 3. ed. New York: CRC Press, 1997.

GOKHALE, S.; KHARE, M. A review of deterministic, stochastic and hybrid vehicular exhaust emission models. International Journal of Transport Management, v. 2, n. 2, p. 59-74, 2004.

GOKHALE, S.; RAOKHANDE, N. Performance evaluation of air quality models for predicting $\mathrm{PM}_{10}$ and $\mathrm{PM}_{25}$ concentrations at urban traffic intersection during winter period. Science of the Total Environment, v. 394, n. 1, p. 9-24, 2008.

GOOGLE MAPS. Disponível em: <http://maps.google.com.br/> Acesso em: 23 jan. 2009.

MEDEIROS, A.M. Bases metodológicas para a incorporação da 
variável ambiental no planejamento da expansão termelétrica no Brasil. Dissertação (Mestrado em Ciências e Planejamento Energético), Universidade Federal do Rio de Janeiro, Rio de Janeiro, 2003.

MISHRA, V.K.; PADMANABHAMUTRY, B. Performance evaluation of CALINE3, CAL3QHC and PART5 in predicting lead concentration in the atmosphere over Delhi. Atmospheric Environment, v. 37, n. 22, p. 3077 3089, 2003.

NAGENDRA, S.M.S.; KHARE, M. Line source emission modeling. Atmospheric Environment, v. 36, n. 13, p. 2083-2098, 2002.

OSSES, M.; DURSBECK, F.; CORVALÁN, R. Modelo de emisión de contaminantes atmosféricos producidos por transporte urbano: el caso de Santiago de Chile. Ciencia Abierta, 2001. Disponível em: <http:// cabierta.uchile.cl/revista/15/articulos/paper3/index.html>. Acessado em 2 ago. 2009

QUEIROZ, P.G.M. Estudos da Poluição do Ar do Município de Sete Lagoas, MG Utilizando Técnicas Nucleares. Dissertação (Mestrado em Ciência e Tecnologia das Radiações, Minerais e Materiais), Centro de Desenvolvimento da Tecnologia Nuclear, Belo Horizonte, MG, 2006.

SÁNCHEZ-CCOYLLO, O.R. et al. Vehicular particulate matter emission in road tunnels in Sao Paulo, Brazil. Environmental Monitoring and Assessment, v. 149, n. 1-4, p. 241-249, 2009.

SEIBERT, P. et al. Review and intercomparison of operational methods for the determination of the mixing height. Atmospheric Environment, v. 34, n. 7, p. 1001-1027, 2000.

SHARMA, P.; KHARE, M. Modelling of vehicular exhausts - a review. Transportation Research Part D: Transport and Environment, v. 6, n. 3, p. 179-198, 2001.

SILVA, M.G. Análise da Qualidade do Ar com base no fluxo de Veículos e variáveis climáticas: o caso da cidade de Uberlândia - MG. Dissertação
(Mestrado em Engenharia Civil), Universidade Federal de Uberlândia, Uberlândia, MG, 2007.

STULL, R.B. An Introduction to Boundary Layer Meteorology. Dordrecht: Kluwer Academic Publishers, 1988.

THERMO ELECTRON CORPORATION. Partisol Model 2000-D Dichotomous Air Sampler. Ohio, USA: Thermo Electron Corporation R \& P Products, 2006.

. A report on emission factors. Washington, DC: USEPA, 1998.

UNITED STATES ENVIRONMENTAL PROTECTION AGENCY (USEPA). Federal Register, Part III, v. 64, $n^{\circ}$. 149. Rules and Regulations: Air Quality Index Reporting. Final Rule. 1999. Disponível em: <http:// www.epa.gov/ttn/oarpg/t1/fr_notices/airqual.pdf $>$. Acesso em: 27 nov. 2008.

. User's guide to CAL3QHC Version 2.0: a modeling methodology for predicting pollutant concentrations near roadway intersections. EPA Publication n. EPA-454/R-92-006. U. S. Environmental Protection Agency, Research Triangle Park, North Carolina 27711, 1995.

Protocol for Determining the Best Performing Model. EPA Publication $n^{\circ}$. EPA-454/R-92-025. Environmental Protection Agency, Pacific Northwest, December, 1992.

WORLD HEALTH ORGANIZATION (WHO). Health effects of transportrelated air pollution. Denmark: World Health Organization, 2005.

YURA, E.A.; KEAR, T.; NIEMEIER, D. Using CALINE dispersion to assess vehicular $\mathrm{PM}_{2.5}$ emissions. Atmospheric Environment, v. 41, n. 38, p. 8747-8757, 2007

ZHOU, H.; SPERLING, D. Traffic emission pollution sampling and analysis on urban streets with high-rising buildings. Transportation Research Part D: Transport and Environment, v. 6, p. 269-281, 2001. 